\title{
A Hospital-Based Cross-Sectional Study Assessing the Relation between Time of Birth and Perinatal Outcome
}

\author{
Mouhamadou Wade1,2*, Papa Moctar Faye ${ }^{1,2}$, Mame Diarra Ndiaye ${ }^{1,2}$, Mamour Gueye ${ }^{1,2}$, \\ Simon Birame Ndour ${ }^{1,2}$, Abdoulaye Diakhate ${ }^{1,2}$, Ndama Niang1,2, Khalifa Fall1,2, Moussa Diallo ${ }^{1,2}$, \\ Omar Gassama ${ }^{1,2}$, Magatte Mbaye ${ }^{1,2}$ \\ ${ }^{1}$ Gynecologic and Obstetric Clinic, Aristide Le Dantec Teaching Hospital, Cheikh Anta Diop University, \\ Dakar, Senegal \\ ${ }^{2}$ Philippe Senghor Health Center, Yoff, Cheikh Anta Diop University, Dakar, Senegal \\ Email: ^mamourmb@yahoo.fr
}

How to cite this paper: Wade, M., Faye, P.M., Ndiaye, M.D., Gueye, M., Ndour, S.B., Diakhate, A., Niang, N., Fall, K., Diallo, M., Gassama, O. and Mbaye, M. (2020) A Hospital-Based Cross-Sectional Study Assessing the Relation between Time of Birth and Perinatal Outcome. Open Journal of Pediatrics, 10, 217-223.

https://doi.org/10.4236/ojped.2020.101021

Received: December 31, 2019

Accepted: March 21, 2020

Published: March 24, 2020

Copyright $\odot 2020$ by author(s) and Scientific Research Publishing Inc. This work is licensed under the Creative Commons Attribution International License (CC BY 4.0).

http://creativecommons.org/licenses/by/4.0/

\begin{abstract}
Objectives: Investigating the relation between perinatal outcomes and hospital working shifts. Methods: We conducted a cross-sectional study at Philippe Maguilen Senghor health center (PMSHC) in Dakar, Senegal from January, $1^{\text {st }} 2011$ to December, 31th 2018. The study population was comprised of all mothers who had delivered at PMSHC and their newborns after completing 22 weeks of gestation. Time of delivery was divided into three periods of working hours: morning shift (deliveries occurred between 7 am and 4:59 $\mathrm{pm}$ ); evening shift from $5 \mathrm{pm}$ to $10: 59 \mathrm{pm}$ and night shift from $11 \mathrm{pm}$ to 6:59 am. Maternal outcomes were assessed by mode of delivery, epsisotomy and perineal injuries. The Apgar scoring system was used to assess newborns at first minute after they were born. Other adverse perinatal outcomes included fresh stillbirth, neonatal referral and early neonatal death. Data were analyzed using Statistical Package for Social Science software (SPSS 24, Mac version). Results: A total of 48,270 mothers and their newborns met eligibility criteria. Caesarean section deliveries were less likely to occur during evening (OR 0.84, 95\% CI; $0.79-0.89, \mathrm{p}=0.001$ ) and night shifts (OR 0.45, CI; $0.47-0.53$, $\mathrm{p}=0.001)$. Evening shift deliveries had 1.1 the odds of poor perinatal outcome (Apgar score < 7) compared to morning shift deliveries (OR 1.1, 95\% CI; $1.02-1.18, \mathrm{p}=0.012$ ). No significant difference was found in the odds of neonate referrals and deaths across the three shifts. Night shift deliveries had 1.1 the odds of perineal injuries compared to morning shift deliveries (OR 1.11, 95\% CI; $1.04-1.18, \mathrm{p}=0.001$, for episiotomy and OR, 1.14; 95\% CI, 1.04 $-1.26, \mathrm{p}=0.008$, for perineal tears). Conclusion: Off-hours deliveries, partic-
\end{abstract}


ularly during the night shift, were significantly associated with higher proportions of perineal injuries compared to morning shift. However, no significant difference was found in the odds of neonate referrals and deaths across the three shifts. Our findings suggest to set up a Neonatology unit at the CSPMS as well as a perinatal network across the country.

\section{Keywords}

Perinatal Outcome, Time of Birth, Low-Resource Setting

\section{Introduction}

Atypical shifts, and particularly night shifts, can be a risk factor for workers. Indeed, the organism is subjected to a so-called circadian rhythm, programmed by an internal clock, and which acts on many physiological activities including food intake, hormonal secretions and the alternation of wakefulness and sleep. In Obstetrics, working on evenings and at night is unavoidable. In addition to these atypical working shifts, stress of working in labor wards increases the risk of error. Previous studies investigating the relation between time of delivery and early intrapartum and neonatal deaths have shown poor outcomes. These complications include fetal injury, perinatal death, and early neonatal death. Other studies have linked intrapartum deaths to admission to the neonatal intensive care unit [1] [2]. In addition, other studies observed a greater risk for deliveries occurring on off-working hours (i.e. evening and night shifts and weekends) compared to working hours [1]-[8].

Very little was found in the literature on the relation between time of delivery and perinatal outcome in developing countries. On this background we compared the prevalence of adverse perinatal outcome across the three hospital working shifts, including the morning shift (7 am - $5 \mathrm{pm})$, evening shift (5 pm $11 \mathrm{pm})$ and night shift (11 pm-7 am).

\section{Methods}

\subsection{Design, Population and Setting}

We conducted a cross-sectional study at Philippe Maguilen Senghor health center (PMSHC) in Dakar, Senegal from January, $1^{\text {st }} 2011$ to December, 31th 2018. PMSHC is a level 2 health center. It does not have the performance of a hospital but surgical procedures are practiced there. Teams of residents in Obstetrics, midwives and nurses provide continuous Obstetric Emergency and Neonatal Care (EmONC). The on-call duties are carried under the supervision of an obstetrician. In 2018, the number of deliveries encountered in our department was 8172 comprising 1500 cesarean sections.

The study population was comprised of all mothers who had delivered at PMSHC and their newborns after completing 22 weeks of gestation. 
The dataset included information on maternal characteristics (age, parity, medical history), obstetric and perinatal outcomes.

Furthermore, time of delivery was divided into three periods of working hours: morning shift (deliveries occurred between 7 am and 4:59 pm); evening shift from $5 \mathrm{pm}$ to $10: 59 \mathrm{pm}$ and night shift from $11 \mathrm{pm}$ to $6: 59 \mathrm{am}$.

\subsection{Outcomes}

Maternal outcomes were assessed by mode of delivery, epsisotomy and perineal injuries.

The Apgar scoring system was used to assess newborns at first minute after they were born. Apgar score was further categorized as less than 7 and greater than or equals to 7. Other adverse perinatal outcomes included fresh stillbirth (birth of a dead fetus without postmortem changes based on physical appearance, including blistered or peeled-off skin), neonatal referral and early neonatal death that is death of a newborn within 7 days post-delivery.

\subsection{Data Analysis}

Data were extracted from E-Perinatal, our electronic medical recording system, and then analyzed using Statistical Package for Social Science software (SPSS 24, Mac version).

Mean, median and standard deviation were considered to describe continuous variables while frequencies were reported for categorical and nominal variables.

Odds ratios and their 95\% confidence interval were computed to see the strength of association between perinatal outcomes and working shifts.

Multiple logistic regression analysis was used to measure independent associations between selected predictors of adverse outcomes in relation to shifts.

\section{Results}

A total of 48,270 mothers and their newborns met eligibility criteria. Mothers' characteristics are shown in Table 1 . The average age of patients was 27 years.

When comparing the distribution of mode of deliveries (Table 1), near one fourth $(23.6 \%)$ of the studied group delivered by caesarean section. Caesarean section deliveries were less likely to occur during evening (OR 0.84, 95\% CI; 0.79 - $0.89, \mathrm{p}=0.001)$ and night shifts (OR $0.45, \mathrm{CI} ; 0.47-0.53, \mathrm{p}=0.001)$ as shown in Table 2.

Evening shift deliveries had 1.1 the odds of poor perinatal outcome (Apgar score $<7$ ) compared to morning shift deliveries (OR 1.1, 95\% CI; $1.02-1.18, \mathrm{p}=$ 0.012 ) while night deliveries were found to be a protective factor. No significant difference was found in the odds of neonate referrals and deaths across the three shifts.

Night shift deliveries had 1.1 the odds of perineal injuries compared to morning shift deliveries (OR 1.11, 95\% CI; $1.04-1.18, \mathrm{p}=0.001$, for episiotomy and OR, 1.14; 95\% CI, $1.04-1.26, \mathrm{p}=0.008$, for perineal tears). 
Table 1. Patients' characteristics.

\begin{tabular}{|c|c|c|c|c|}
\hline & Morning shift & Evening shift & Night shift & Total \\
\hline \multicolumn{5}{|c|}{ Age } \\
\hline \multirow{2}{*}{$\geq 35$ years } & 2351 & 1264 & 1845 & 5460 \\
\hline & $15.6 \%$ & $14.1 \%$ & $14.8 \%$ & $15.0 \%$ \\
\hline \multirow{2}{*}{$<35$ years } & 12,700 & 7673 & 10,638 & 31,011 \\
\hline & $84.4 \%$ & $85.9 \%$ & $85.2 \%$ & $85.0 \%$ \\
\hline \multicolumn{5}{|c|}{ Parity } \\
\hline \multirow{2}{*}{ Multiparous } & 9277 & 5314 & 7574 & 22,165 \\
\hline & $61.6 \%$ & $59.5 \%$ & $60.7 \%$ & $60.8 \%$ \\
\hline \multirow{2}{*}{ Nulliparous } & 5774 & 3623 & 4909 & 14,306 \\
\hline & $38.4 \%$ & $40.5 \%$ & $39.3 \%$ & $39.2 \%$ \\
\hline \multicolumn{5}{|c|}{ Admission } \\
\hline \multirow{2}{*}{ Direct admission } & 12,340 & 7162 & 10,239 & 29,741 \\
\hline & $82.0 \%$ & $80.1 \%$ & $82.0 \%$ & $81.5 \%$ \\
\hline \multirow{2}{*}{ Referral } & 2711 & 1775 & 2244 & 6730 \\
\hline & $18.0 \%$ & $19.9 \%$ & $18.0 \%$ & $18.5 \%$ \\
\hline \multicolumn{5}{|c|}{ Type of pregnancy } \\
\hline \multirow{2}{*}{ Multiple } & 523 & 278 & 329 & 1130 \\
\hline & $3.5 \%$ & $3.1 \%$ & $2.6 \%$ & $3.1 \%$ \\
\hline \multirow{2}{*}{ Singleton } & 14,528 & 8659 & 12,154 & 35,341 \\
\hline & $96.5 \%$ & $96.9 \%$ & $97.4 \%$ & $96.9 \%$ \\
\hline \multicolumn{5}{|c|}{ Presentation } \\
\hline \multirow{2}{*}{ Vertex } & 14,139 & 8441 & 11,880 & 34,460 \\
\hline & $93.9 \%$ & $94.5 \%$ & $95.2 \%$ & $94.5 \%$ \\
\hline \multirow{2}{*}{ Malpresentation } & 912 & 496 & 603 & 2011 \\
\hline & $6.1 \%$ & $5.5 \%$ & $4.8 \%$ & $5.5 \%$ \\
\hline \multicolumn{5}{|c|}{ Infant condition } \\
\hline \multirow{2}{*}{ Alive } & 14,545 & 8582 & 12,050 & 35,177 \\
\hline & $96.7 \%$ & $96.1 \%$ & $96.6 \%$ & $96.4 \%$ \\
\hline \multirow{2}{*}{ Fresh stillborn } & 261 & 164 & 193 & 618 \\
\hline & $1.7 \%$ & $1.8 \%$ & $1.5 \%$ & $1.7 \%$ \\
\hline Macerated still- & 245 & 191 & 240 & 676 \\
\hline birth & $1.6 \%$ & $2.1 \%$ & $1.9 \%$ & $1.9 \%$ \\
\hline
\end{tabular}

Table 2. Perinatal outcome of current delivery according to three shifts of $24 \mathrm{~h}$.

\begin{tabular}{|c|c|c|c|c|c|c|c|c|}
\hline \multirow[t]{4}{*}{ Outcome } & \multicolumn{8}{|c|}{ Time of delivery } \\
\hline & \multicolumn{2}{|c|}{ Morning shift } & \multicolumn{3}{|c|}{ Evening shift } & \multicolumn{3}{|c|}{ Night shift } \\
\hline & $\mathrm{N}$ & OR & $\mathrm{N}$ & OR & & $\mathrm{N}$ & OR & \\
\hline & $\%$ & $95 \% \mathrm{CI}$ & $\%$ & $95 \% \mathrm{CI}$ & $\mathrm{p}$ & $\%$ & $95 \% \mathrm{CI}$ & $\mathrm{p}$ \\
\hline \multirow{2}{*}{ Cesarean section } & 4326 & \multirow{2}{*}{1} & 2263 & 0.84 & \multirow{2}{*}{0.001} & 2092 & 0.45 & \multirow{2}{*}{0.001} \\
\hline & 28.7 & & 25.3 & $0.79-0.89$ & & 16.8 & $0.47-0.53$ & \\
\hline \multirow{2}{*}{ Apgar score $<7$} & 2076 & \multirow{2}{*}{1} & 1338 & 1.1 & \multirow{2}{*}{0.012} & 1682 & 0.97 & \multirow{2}{*}{0.44} \\
\hline & 13.8 & & 15 & $1.02-1.18$ & & 13.5 & $0.9-1.04$ & \\
\hline \multirow{2}{*}{ Neonate referral } & 67 & \multirow{2}{*}{1} & 58 & 1.46 & \multirow{2}{*}{0.035} & 46 & 0.83 & \multirow{2}{*}{0.32} \\
\hline & 0.4 & & 0.6 & $1.03-2.08$ & & 0.4 & $0.57-1.21$ & \\
\hline \multirow{2}{*}{ Neonatal death } & 57 & \multirow{2}{*}{1} & 26 & 0.77 & \multirow{2}{*}{0.24} & 51 & 1.08 & \multirow{2}{*}{0.70} \\
\hline & 0.4 & & 0.3 & $0.48-1.22$ & & 0.4 & $0.74-1.58$ & \\
\hline \multirow{2}{*}{ Episiotomy } & 2718 & \multirow{2}{*}{1} & 1633 & 1.01 & \multirow{2}{*}{0.68} & 2452 & 1.11 & \multirow{2}{*}{0.001} \\
\hline & 18.1 & & 18.3 & $0.95-1.09$ & & 19.6 & $1.04-1.18$ & \\
\hline \multirow{2}{*}{ Perineal injury } & 845 & \multirow{2}{*}{1} & 541 & 1.08 & \multirow{2}{*}{0.16} & 796 & 1.14 & \multirow{2}{*}{0.008} \\
\hline & 5.6 & & 6.1 & $0.96-1.21$ & & 6.4 & $1.04-1.26$ & \\
\hline
\end{tabular}

OR: Odds ratio, CI: Confidence Interval. 


\section{Discussion}

Evening and night shifts were associated with adverse maternal outcomes including episiotomy and perineal injuries when compared with the morning shift. However, poor perinatal outcome was not significantly associated with time of delivery.

Our results are in line with previous studies [9] although refuted by others from resource limited-settings [10].

\section{- Relation between caesarean section and time of delivery}

Rates of cesarean deliveries during night and evening shifts found in this study were lower to that of morning shift; prophylactic caesareans excluded. Our findings are in line with Mgaya results who did not find any significant difference between the distribution of cesarean deliveries in regard with the time of delivery ( $48 \%$ at night, $47 \%$ in the evening and $46 \%$ during the day) [10]. We did not expect such findings as one of our hypotheses was that the relatively limited human and physical resources during the evening and the shifts compared to the morning could elevate the rate of caesarean section as well as poor outcomes during off-hours. One of the explanations might be that the morning shift is spread over 9 hours while those for evening and night are spread over 6 and 8 hours respectively.

\section{- Perinatal outcome}

Neonate referrals and deaths of newborns were more likely to occur during the morning shift than in the evening. PMSHC has only one neonatal pediatrician for 7,000 to 8,000 deliveries per year. To mitigate this lack of human resources, our department had engaged in task-shifting with the training of nurses who provide Emergency neonatal care. Even if the task shifting is to be welcomed, these nurses are very quickly limited to recognizing and dealing adequately with situations such as neonatal distress or the recognition of certain emergency situations which require immediate referral. One might argue that a department with only one pediatrician should not perform the delivery of certain women and/or newborns at high risk. Here is the place to issue a distress call regarding the management of risky pregnancies in Dakar. Only three maternity units are equipped to properly take care of newborns in Dakar. One does not have maternity ward and is limited by the number of beds/incubators. Access to the two other departments is limited by the daily cost of hospitalization, which varies between FCFA 35,000 (\$65) and FCFA 50,000 (\$90). In addition, no guideline clearly provides information for organizing efficiently perinatal healthcare in Senegal.

It seems clear that at least some of the adverse outcomes that occur in obstetrics are preventable and that the root causes of these preventable events such as neonatal death, although multiple, often involve a teamwork [11]. In France, for instance, maternity units provide obstetric and neonatal care according to their quality components. Three maternity levels can be described. Extreme premature and the small for gestational age newborns benefit from a birth in a type III 
maternity in order to decrease the risks of mortality and morbidity.

For such an organization to properly work in our country, patients should have a valid health insurance available in all maternity units where they are likely to be staying. It is common some patients suffering from severe preeclampsia forgo perinatal care (maternal transfer) for financial reasons.

Whereas in developed countries rationing is performed by using various strategies such as denial, selection, delay, deterrence, deflection or dilution, rationing in our limited-resource settings is mainly by ability to pay at the point of delivery. Direct payment by patient, the worst health financing system, must be addressed in order to provide patients and their newborns with adequate healthcare.

The need for multidisciplinary neonatal care in the event of fetal malformation (congenital diaphragmatic hernia, omphalocele, transposition of great arteries) also justify an antenatal orientation towards appropriate maternity.

Poor prenatal outcomes in our study is partly explained by this situation which need to be improved by upgrading out department in order to provide patients with pediatricians available 24 hours/day.

\section{- Strengths and weaknesses of the study}

This study reports data from patients whose outcome is already known. The recording is retrospective and continuous and does not only involve the parameters studied in the study but also a large number of socio-demographic, obstetrical and neonatal parameters. For these reasons and given the sample size, we can consider the data from this study to be reliable. However, there may still be biases because of the type of study.

\section{Conclusions}

Off-hours deliveries, particularly during the night shift, were significantly associated with higher proportions of perineal injuries compared to morning shift. However, no significant difference was found in the odds of neonate referrals and deaths across the three shifts.

Our findings suggest to set up a Neonatology unit at the CSPMS and redeploy a part of the Neonatology staff (dependent on the Chair of Pediatrics) to the CSPMS in view of the number of deliveries recorded by the structure and finally work to set up a perinatal network.

\section{Conflicts of Interest}

The authors declare no conflicts of interest regarding the publication of this paper.

\section{References}

[1] Paccaud, F., Martin-Beran, B. and Gutzwiller, F. (1988) Hour of Birth as a Prognostic Factor for Perinatal Death. Lancet, 1, 340-343. https://doi.org/10.1016/S0140-6736(88)91130-0

[2] Urato, A.C., Craigo, S.D., Chelmow, D. and O’Brien, W.F. (2006) The Association 
between Time of Birth and Fetal Injury Resulting in Death. American Journal of Obstetrics and Gynecology, 195, 1521-1526.

https://doi.org/10.1016/j.ajog.2006.03.084

[3] Gijsen, R., Hukkelhoven, C., Schipper, M., Ogbu, U., De Bruin-Kooistra, M. and Westert, G. (2012) Effects of Hospital Delivery during Off-Hours on Perinatal Outcome in Several Subgroups: A Retrospective Cohort Study. BMC Pregnancy Childbirth, 12, 92. https://doi.org/10.1186/1471-2393-12-92

[4] De Graaf, J.P., Ravelli, A.C., Visser, G.H., Hukkelhoven, C., Tong, W.H., Bonsel, G.J., et al. (2010) Increased Adverse Perinatal Outcome of Hospital Delivery at Night. BJOG, 117, 1098-1107. https://doi.org/10.1111/j.1471-0528.2010.02611.x

[5] Geburtshilfe, Z. (2003) Why Are Babies Born at Night at Increased Risk of Early Neonatal Mortality? Neonatal, 207, 137-142.

[6] Bendavid, E., Kaganova, Y., Needleman, J., Gruenberg, L. and Weissman, J.S. (2007) Complication Rates on Weekends and Weekdays in US Hospitals. The American Journal of Medicine, 120, 422-428. https://doi.org/10.1016/j.amjmed.2006.05.067

[7] Stephansson, O., Dickman, P.W., Johansson, A.L., Kieler, H. and Cnattingius, S. (2003) Time of Birth and Risk of Intrapartum and Early Neonatal Death. Epidemiology, 4, 218-222. https://doi.org/10.1097/01.EDE.0000037975.55478.C7

[8] Heller, G., Misselwitz, B. and Schmidt, S. (2000) Early Neonatal Mortality, Asphyxia Related Deaths, and Timing of Low Risk Births in Hesse, Germany, 1990-8: Observational Study. iBritish Medical Journal, 321, 274-275.

https://doi.org/10.1136/bmj.321.7256.274

[9] Tavares, S., Cavaco-Gomes, J., Moucho, M., Severo, M., Mateus, M., Ramalho, C., et al. (2017) 24/7 Presence of Medical Staff in the Labor Ward; No Day-Night Differences in Perinatal and Maternal Outcomes. The American Journal of Perinatology, 34, 529-534. https://doi.org/10.1097/01.ogx.0000526816.16579.d4

[10] Mgaya, A. (2017) Is Time of Birth a Predictor of Adverse Perinatal Outcome? A Hospital-Based Crosssectional Study in a Low-Resource Setting, Tanzania. BMC Pregnancy and Childbirth, 17, 184. https://doi.org/10.1186/s12884-017-1358-9

[11] Gabbe, S.G., Niebyl, J.R., Simpson, J.L., Landon, M.B., Galan, H.L., Jauniaux, E.R.M., et al. (2016) Obstetrics. Normal and Problem Pregnancies. 7th Edition, Elsevier, Amsterdam. 